ORIGINAL ARTICLE

\title{
PERCEPTIONS AND COMPARISON OF BEDSIDE TEACHING AMONG FINAL YEAR STUDENTS OF PUBLIC AND PRIVATE MEDICAL COLLEGES OF PESHAWAR
}

Humera Adeeb $^{1}$, Brekhna Jamil ${ }^{1}$, Ihsan Ullah ${ }^{2}$, Muhammad Junaid Khan ${ }^{3}$

Submitted: April 26, 2021
Accepted: June 02, 2021
Published: June 30, 2021
Authors' Affiliation
${ }^{1}$ Institute of Health Professions
Education and Research,
Khyber Medical University
Peshawar, Pakistan Pathology and
${ }^{2}$ Institute of Phyber
Diagnostic Medicine Khe
Medical University, Peshawar
${ }^{3}$ Medical Education Department,
Ayub Medical College
Abbottabad

Corresponding Author

Dr Ihsan Ullah

Institute of Pathology and Diagnostic Medicine,

Khyber Medical University

Peshawar, Pakistan

Email:

drihsan.ibms@kmu.edu.pk

\author{
ABSTRACT \\ Introduction: Bedside teaching is very important, however, there seems a decline \\ in this strategy. The regulatory authority's focus on the 'infrastructure' of an \\ institute is indeed very important, however, this needs to be supplemented by a \\ greater emphasis on the quality of bedside teaching.
}

Material \& Methods: A cross-sectional study was conducted in four medical colleges of Peshawar during the month of February, 2020. In order to complete this study, the Rensis Likert theory was kept in mind where a questionnaire with thirtythree questions was prepared. The questioner focused on physical environment, patient's comfort, student's attitude and teaching session which was then distributed among 242 students from all four colleges. Mean score for each question and each subscale was calculated for each institute for perceptions. Mean score of two public and two private institutes for each subscale was compared by unpaired $t$-test. A $p$-value $\leq 0.05$ was considered statistically significant.

Results: Khyber Girls Medical College scored $(2.97 \pm 0.50)$ for having a better physical environment, nonetheless, the college also had highest respondent when it was evaluated for teaching sessions. In addition, for the teaching fellow components of the study, the same collage reported the highest score $(3.70 \pm 0.67)$. Khyber Medical College scored lowest in the area of teaching sessions. On the other hand, Patients' comfort and students' attitude in all four colleges had similar results. For physical environment, there was significant difference between both the medical colleges in public and private sectors.

Conclusion: The study reveals that the average scores in four subscales of the selected tool are comparable in the studied medical institutes with some variations. However, there are pronounced distinctions when it comes to physical environment and teaching fellow subscales.

Key Words: Bedside teaching, physical environment, teaching session, teaching fellow

The authors declared no conflict of interest and agreed to be accountable for all aspects of the work in ensuring that questions related to the accuracy or integrity of any part of the work are appropriately investigated and resolved. All authors contributed substantially to the planning of research, question designing, data collection, data analysis and writeup of the article.

This article may be cited as: Adeeb H, Jamil B, Ullah I, Khan MJ. Perceptions and comparison of bedside teaching among final year students of public and private medical colleges of Peshawar. Rehman J Health Sci. 2021;3(1). 38-42

\section{INTRODUCTION}

There are 44 medical colleges in public sector and 70 in private sector in Pakistan. ${ }^{1}$ With increasing number of medical colleges being given accreditation by Pakistan Medical Commission, an emphasizes on the evaluation of infrastructure and faculty is given while translating, the effects of infrastructure and faculty into quality of education has been neglected. Bedside teaching method has been one of the most efficient way of teaching a group of students on actual patient. ${ }^{2}$ It is integral part of multidimensional teaching in clinical years. Bedside teaching requires three essential stakeholders, the patient, students and tutor. These stakeholders are ineffective unless they are linked by a properly planned, wellstructured teaching session. ${ }^{3,4}$ Due to increasing utilization of modern technology in diagnosis, teaching from bedside has been shifted to conference, seminar rooms and skill laboratories. As a result, bedside teaching has declined dramatically. ${ }^{4-6}$.

The decline in quantity of bedside teaching has resulted in poorly physical diagnosis skills in junior doctors. This declining trend attributes to multiple responsibilities of faculty members, emerging utilization of medical technology and simulation techniques as a teaching strategy. ${ }^{7}$ Thus, resulting in less work burden on the faculty and reducing patient stay in the hospitals. ${ }^{4,8,9}$ A number of factors identified for dwindling bedside teaching which included lack of curriculum for bedside teaching, poor job satisfaction and lack of incentives. ${ }^{8,10,11}$

Students and post graduate trainee's find bedside teaching as an opportunity for learning and enhancing their clinical skills. Students improves their communication skills, learns about humanistic nature of patient care and receive immediate feedback and formative assessment at bedside. ${ }^{7}$ Tutors and patients interaction in bedside teaching strengthens students ability to better diagnosis and give them an opportunity to learn professionalism and bedside manners. ${ }^{9}, 10,12$ Lack of patients' students interaction during the patient stay in a hospitals, existence of large number of students in study groups, lack of suitable study and learning environment are some of the barriers to effective learning of clinical skills at bedside. ${ }^{13}$

There is scarcity of evidence regarding perception and comparison of bedside teaching in both private and public sector medical colleges. This study was design to assess and compare perception of bedside teaching in private and public sector medical colleges which might provide an 
opportunity to educators in order to analyse the current state of bedside teaching and a stepping stone for further research. The objective of the study was to determine student's perceptions about bedside teaching and to compare bedside teaching in private and public sector medical colleges of Peshawar.

\section{MATERIAL AND METHODS}

This was a cross-sectional study carried out at two private [Kabir Medical College (KbMC) and Pak International Medical College Peshawar (PIMC)] and two public sectors [Khyber Medical College (KMC), Khyber Girls Medical College (KGMC)]. Two questionnaires were used to collect data from final year Bachelor of Medicine and Bachelor of Surgery (MBBS) students during the month of February, 2020. Data was analysed using SPSS version 20. First questionnaire used consisted of 12 items 4 points Likert scale with little modification from a paper published in Bangladesh. ${ }^{14}$ These 12 items were further categorized into two subscales in order to measure physical environment of bedside teaching, patients' comfort and students' attitude towards patients. The second questionnaire which was used for this study consisted of 18 items 5-points Likert scale which was also adopted. The 18 items were further divided into two subscales; teaching session and teaching fellow. This tool has reliability index of 0.71 . This questionnaire was provided by Katharina Dreiling. ${ }^{15}$

For a population of 600 students in the final year of four medical colleges, population proportion formula was used. At $5 \%$ margin of error and $95 \%$ confidence interval, sample size calculated was 235 participants. About 70 students from each institute were approached for collection of data to avoid problems of attrition and incomplete questionnaires. Sampling was done by non-probability convenience sampling. Ethical approval was given by the institutes for this study. Students were approached right after the completion of their ward teaching sessions in hospital or at the end of their lectures to collect data.

Written informed consent was obtained from the participants. Students were provided with selfadministered questionnaires which was collected on the spot. Students were asked to fill in the questionnaire, keeping in mind the best bedside teaching session they had in last seven days. Students attending wards for less than seven days were excluded. For each subscale, responses to items were summed up and mean score with standard deviation was calculated for each institute separately. In the next step, mean scores of two private and two public sector medical colleges was grouped for each subscale and compared by independent $t$-test. A $p$ value $\leq 0.05$ was considered statistically significant.

\section{RESULTS}

A total of 242 final year students with the average age of 22.97 years was selected for the study. Since one of the public medical college was exclusively for females, therefore the study addressed as many as 130 females $(57.40 \%)$ and 103 male $(42.60 \%)$ students (table 1). Highest response rate $(97.14 \%)$ came from KGMC and lowest from PIMC (75.71\%). Students from medicine departments in study population were $4.5 \%$ more than students from surgical. Average number of students in a batch at bedside was around 17 at KGMC, 13 at KMC, 14 at PIMC and 23 at KbMC. Among faculty $28.1 \%$ teaching session were taken by associate professors, $26.4 \%$ by professors, $23.6 \%$ by assistant professors and $21.9 \%$ by senior registrars.

In the physical environment subscale, the highest mean score was reported by students from KGMC (2.97) and lowest by KbMC (2.42), the mean score of KMC and PIMC was equal. In the subscale patients' comfort and students' attitude, the mean score of KGMC, KMC and PIMC was approximately equal as shown in table 2.

In the teaching session subscale, the highest mean score was reported by KGMC and lowest by KMC. In the subscale teaching fellow, the highest mean score was reported by student of KGMC (3.70) followed by KMC (3.38) and the lowest by KbMC (2.85) as shown in table 3. The mean score of two public sector medical colleges was compared with mean score of two private medical colleges by independent t-test for each subscale. In physical environment scale there was significant difference in the mean score of public $2.87( \pm 0.48)$ and private colleges $2.59( \pm 0.60)$ with $p$-value $=0.0001$. There was significant difference in the subscale, teaching fellow with mean score of public group $3.55( \pm 0.50)$ and $3.04( \pm 0.68)$ by medical colleges in private sector with $\mathrm{p}$-value $=0.0001$. The mean scores similar between the two groups in students' attitude and teaching sessions subscales as shown in table 4

\section{DISCUSSION}

As William Osler (1849-1919) rightly said, 'Medicine is learned by the bedside and not in the classroom'. ${ }^{16}$ Despite the fact that bedside teaching proves to be one of the most important component of teaching and learning, yet it is gradually declining in medical education. ${ }^{4}$ With an increase in number of medical colleges there seems dire need for better evaluation and assessment of bedside teaching which may improve quality of clinical teaching. In this study, students reported in details the different aspects of bedside teaching. According to the subscales, the overall response was positive, though mean scores of four institutes varied. For physical environment, mean score was less than 3 in three institutes. Number of students was considered as a hampering factor in physical environment of bedside teaching. These findings are consistent with some regional studies. ${ }^{12-14,17}$

For patients' comfort and students' attitude, mean score was more than 3 at KMC, KGMC and PIMC and less than 3 at $\mathrm{KbMC}$. This is congruous with a study in Bangladesh except differences in communicating findings to patients where mean score in this study was reported less than $3 .^{14}$ For teaching sessions, mean score and mean score of most individual responses was more than 3 . There was lack of opportunity to examine patients in teaching sessions at two private institutes where mean score was less than 3 . This is in accordance to some of the studies reported earlier ${ }^{18}$. Dundee Ready Educational Environment Measure (DREEM) questionnaire has been used to assess student's perception of teaching. Significant differences were found according to gender of students ${ }^{19}$.

In the category of teaching fellow sessions, KGMC and KMC had scored more than 3 in all aspects. PIMC had same score except in enhancing interest in subject, providing opportunities to apply theoretical knowledge. Similar literature reported by study from Kingdom of Saudi Arabia, Malaysia, Australia as measured by DREEM. ${ }^{20-22}$ Mean score was less than 3 for $\mathrm{KbMC}$ in all aspects. One public sector college in remote area of Punjab 
reported negative perceptions about all aspects by DREEM scale. $^{23}$

The highly significant difference $(\mathrm{p}=0.0001)$ in physical environment and teaching fellow, at bedside teaching between public and private institutes calls for an in-depth, large sample and qualitative evaluation in order to understand the root cause of this difference. Suitable physical environment, facilitates educational environment which in return affects students' academic achievements and motivation. ${ }^{24}$ While assessing findings related to students, students' bias towards a friendly teacher, attractiveness and personality needs to be kept in mind. ${ }^{25}$ Perception of teachers as assessed by DREEM has shown significant differences with respect to gender and study year of students. ${ }^{19}$ Teachers in Asian countries have influential power over shaping of the learning environment. Being knowledgeable, punctual and respectful communicator is what mostly appreciated by students. The development of these attributes can alleviate their impact on students. ${ }^{26}$

\section{CONCLUSION}

Students' perceptions about bedside teaching in four institutes on the four subscales are comparable with some variation according to different questions. There are significant differences in the physical environment at bedside teaching and teaching fellow subscale between public and private medical colleges. This study highlights the dire needs of a detailed qualitative research to be conducted. A censes or qualitative study involving more institutes is recommended to look for robust evidence regarding differences in bedside teaching.

Acknowledgement: Dr. Jobaida Sultana, Associate Professor; Department of Obstetrics and Gynecology, Shaheed Suhrawardy Medical College \& Hospital, Dhaka, Bangladesh. I have used questionnaire with some modifications with prior permission of the author.

Katharina Dreiling, MSc, is an educational scientist at Geottingen, University Medical Centre Germany, for providing bedside teaching questionnaire.

Dr Ahsan Sethi, Assistant Professors at Institute of Health Profession Education, Khyber Medical University, Peshawar for remaining available for guidance during writing this article.

\section{REFERENCES}

1. List of medical schools in Pakistan. Mar 5, 2020. Accessed Mar 2020. https://en.wikipedia.org/wiki/List_of_medical_schools in Pakistan

2. Sethi A, Javaid A. Accreditation System and Standards for Medical Education in Pakistan: It's time we raise the bar. Pakistan Journal of Medical Sciences. NovDec 2017;33(6):1299-1300. doi:10.12669/pjms.336.14178 3. Garout M, Nuqali A, Alhazmi A, Almoallim H. Bedside teaching: an underutilized tool in medical education. Int $J$ Med Educ. 2016;7:261-262. doi:10.5116/ijme.5780.bdba

4. Peters M, Ten Cate O. Bedside teaching in medical education: a literature review. Perspectives on Medical Education. 2014;3(2):76-88. doi:10.1007/s40037013-0083-y

5. Crumlish CM, Yialamas MA, McMahon GT. Quantification of bedside teaching by an academic hospitalist group. Journal of hospital medicine. May 2009;4(5):304-7. doi:10.1002/jhm.540
6. Shehab A. Clinical Teachers' Opinions about Bedside-based Clinical Teaching. Sultan Qaboos University Medical Journal. 2013;13(1):121-126. doi:10.12816/0003205

7. Ramani S, Orlander JD. Human dimensions in bedside teaching: focus group discussions of teachers and learners. Teach Learn Med. 2013;25(4):312-318. doi:10.1080/10401334.2013.827979

8. Salam A, Siraj HH, Mohamad N, Das S, Rabeya Y. Bedside teaching in undergraduate medical education: issues, strategies, and new models for better preparation of new generation doctors. Iran J Med Sci. 2011;36(1):1-6.

9. Kohli V, Dhaliwal U. Medical students' perception of the educational environment in a medical college in India: a cross-sectional study using the Dundee Ready Education Environment questionnaire. J Educ Eval Health Prof. 2013;10:5-5. doi:10.3352/jeehp.2013.10.5

10. Khan I. Bedside Teaching-Making it an effective Instrucitional tool. Journal of Ayub Medical College. 07/01 2014;26:286-9.

11. Gimson A, Javadzadeh S, Doshi A. Bedside teaching: everybody's but nobody's responsibility. Adv Med Educ Pract. 2019;10:357-359. doi:10.2147/AMEP.S181877

12. Sultan AS. Bedside teaching: An indispensible tool for enhancing the clinical skills of undergraduate medical students. Journal of Pakistan Medical Association. Feb 2019;69(2):235-240.

13. Nandini C SD, Kaushik M, Chandan C. Students' and Teachers' Perceptions of Factors Leading to Poor Clinical Skill Development in Medical Education: A Descriptive Study, . Education Resaerch International. 10/25 2015;1doi:10.1155/2015/12402

14. Sultana J, Ara, I., Talukder, M. H., Khan, M. M., Sultana, M., \& Munira, S. Students' Perception about Status of Bedside Teaching in Undergraduate Medical Education of Bangladesh. Journal of Bangladesh College of Physicians and Surgeons,. 2017;35(4): 163-169. . doi:doi.org/10.3329/jbcps.v35i4.34735

15. Dreiling $\mathrm{K}$, Montano $\mathrm{D}$, Poinstingl $\mathrm{H}$, et al. Evaluation in undergraduate medical education: Conceptualizing and validating a novel questionnaire for assessing the quality of bedside teaching. Medical Teacher. Aug

doi:10.1080/0142159x.2017.1324136

16. Stone MJ. The wisdom of Sir William Osler. Am J Cardiol. 1995;75(4):269-276. doi:10.1016/00029149(95)80034-p

17. Roslan NAL, Tang BJJ, Bohan NS, Veerakumar $\mathrm{H}$, Kendong SMA, Talip SB. The perception of medical students in clinical years towards bedside teaching in Universiti Malaysia Sarawak (UNIMAS). Journal of Borneo-Kalimantan.

2016;2(2)doi:org/10.33736/jbk.474.2016

18. Nawabi S, Maqsood A, Javaid M. Comparative performance of public and private sector health education in Pakistan: Parent's perspective. International Journal of Advanced Research. 12/05 2018;6:612-19. doi:10.21474/IJAR01/8037

19. Aneela Umber SK, Musarrat-ulHussnaian,Sumaira Ihsan. Educational Environment at University Medical and Dental College, FSD. Annals of King Edward Medical University. 2011;17(3):292-298. 
20. Soliman MM, Sattar K, Alnassar S, et al. Medical students' perception of the learning environment at King Saud University Medical College, Saudi Arabia, using DREEM Inventory. Adv Med Educ Pract. 2017;8:221-227. doi:10.2147/AMEP.S127318

21. Amaranathan A, Dharanipragada K, Lakshminarayanan S. Medical students\&\#8217; perception of the educational environment in a tertiary care teaching hospital in India. Medical Education. The National Medical Journal of India. July 1, 2018 2018;31(4):231-236. doi:10.4103/0970-258x.258226

22. Ajaya Kumar Dhakal DS, Suraj Bajracharya, Amita Pradhan, Balman Singh Karki, Sanjaya Dhakal Perceptions of Medical Students About Bedside Teaching in a Medical. Journal of Nepal Medical Association. 2018;56(211):640-645.

23. Anwar MS AI, Ghafoor T.. . Medical students' per-ceptions of educational environment in remote and urban area medical colleges of Punjab, Pakistan. Advances in Health Profession Education. 2015;1:18-23.

24. Imran N, Khalid F, Haider II, et al. Student's perceptions of educational environment across multiple undergraduate medical institutions in Pakistan using DREEM inventory. JPMA The Journal of the Pakistan Medical Association. 2015;65(1):24-28.

25. El-Sayed M, Simon MA, El-Wasify M, Nambiar V. Medical students' perception of teaching evaluation and feedback: a study at Oman Medical College. Middle East Current Psychiatry. 2018;25(3):131-134. doi:10.1097/01.XME.0000534676.55060.8d

26. Burgess A, Goulston K, Oates K. Role modelling of clinical tutors: a focus group study among medical students. BMC Medical Education. 2015/02/14 2015;15(1):17. doi:10.1186/s12909-015-0303-8

Table 1: average age, gender distribution and specialty of students attended bedside session

\begin{tabular}{|lcc|}
\hline Age of students & Range & Mean \\
Years & $22-27$ & $22.97( \pm 0.85)$ \\
Gender & Frequency & Percentage \\
Male & 103 & 42.60 \\
Female & 139 & 57.40 \\
Total & 242 & 100 \\
Speciality & Frequency & Percentage \\
Medicine and allied & 127 & 52.50 \\
Surgery and allied & 115 & 47.50 \\
\hline
\end{tabular}

Table 2: Mean score for each response and $\mathrm{X} \pm \mathrm{SD}$ for physical environment and patient comfort, students' attitude

\begin{tabular}{|c|c|c|c|c|c|}
\hline $\mathbf{S} / \mathbf{N}$ & Questions & $\begin{array}{l}\text { KGMC } \\
(\mathbf{n - 6 8})\end{array}$ & $\begin{array}{l}\text { KMC } \\
(\mathbf{n}-60)\end{array}$ & $\begin{array}{r}\text { PIMC } \\
(\mathbf{n}-53)\end{array}$ & $\begin{array}{c}\text { KbMC } \\
(\mathbf{n}-60)\end{array}$ \\
\hline & Physical environment at bedside & & & & \\
\hline 1 & The temperature was comfortable. & $3.22 \pm 0.68$ & $3.10 \pm 0.83$ & $2.59 \pm 0.94$ & $2.40 \pm 0.86$ \\
\hline 2 & $\begin{array}{l}\text { There was no disturbance; I had sufficient } \\
\text { scope to clearly listen the patients' and } \\
\text { teacher's words. }\end{array}$ & $2.93 \pm 0.69$ & $2.82 \pm 0.77$ & $2.70 \pm 0.94$ & $2.28 \pm 0.76$ \\
\hline 3 & The light was sufficient. & $2.60 \pm 081$ & $2.15 \pm 0.82$ & $2.43 \pm 0.86$ & $2.28 \pm 0.88$ \\
\hline 4 & $\begin{array}{l}\text { There was adequate space to stand beside the } \\
\text { patient so I had Sufficient scope to observe all } \\
\text { the activities. }\end{array}$ & $3.24 \pm 0.69$ & $3.15 \pm 0.77$ & $3.15 \pm 0.92$ & $2.75 \pm 0.85$ \\
\hline \multirow[t]{3}{*}{5} & $\begin{array}{l}\text { Student number was not large so everybody } \\
\text { had the chance to participate actively. }\end{array}$ & $2.87 \pm 0.99$ & $2.65 \pm 0.95$ & $3.00 \pm 0.89$ & $2.42 \pm 1.03$ \\
\hline & $\begin{array}{l}\text { Overall mean } \pm \text { standard deviation of } \\
\text { subscale }\end{array}$ & $2.97 \pm 0.50$ & $2.77 \pm 0.44$ & $2.78 \pm 0.62$ & $2.42 \pm 0.53$ \\
\hline & Patient comfort and students' attitude & & & & \\
\hline 6 & Informed consent was taken from the patient. & $3.38 \pm 0.67$ & $3.12 \pm 0.92$ & $3.28 \pm 0.85$ & $2.95 \pm 0.92$ \\
\hline 7 & I was properly introduced to the patient & $3.10 \pm 0.67$ & $3.13 \pm 0.65$ & $2.91 \pm 0.93$ & $2.65 \pm 1.02$ \\
\hline 8 & We maintained privacy of the patient & $3.15 \pm 0.73$ & $3.05 \pm 0.98$ & $3.35 \pm 0.67$ & $2.95 \pm 1.04$ \\
\hline 9 & All the findings were explained to the patient. & $2.65 \pm 0.82$ & $2.72 \pm 0.84$ & $2.63 \pm 0.80$ & $2.50 \pm 0.96$ \\
\hline 10 & $\begin{array}{l}\text { We responded to the patient's question } \\
\text { appropriately }\end{array}$ & $2.85 \pm 0.62$ & $2.97 \pm 0.78$ & $2.96 \pm 0.61$ & $2.65 \pm 1.03$ \\
\hline 11 & $\begin{array}{l}\text { We always sympathized to patient and paid } \\
\text { due attention to his/her discomfort and } \\
\text { emotion. }\end{array}$ & $3.07 \pm 0.67$ & $3.10 \pm 0.73$ & $3.22 \pm 0.86$ & $3.00 \pm 0.92$ \\
\hline \multirow[t]{2}{*}{12} & $\begin{array}{l}\text { We said thanks to the patient for } \\
\text { participation. }\end{array}$ & $3.40 \pm 0.67$ & $3.23 \pm 0.87$ & $3.13 \pm 0.97$ & $2.90 \pm 0.87$ \\
\hline & Overall mean \pm standard deviation of subscale & $3.08 \pm 0.40$ & $3.04 \pm 0.59$ & $3.09 \pm 0.54$ & $2.80 \pm 0.75$ \\
\hline
\end{tabular}


Table 3: Mean score for each response and $\mathrm{X} \pm \mathrm{SD}$ for teaching session and teaching fellow

\begin{tabular}{|c|c|c|c|c|c|}
\hline & Teaching session & KGMC & KMC & PIMC & KbMC \\
\hline 13 & $\begin{array}{l}\text { The degree of difficulty of session was well } \\
\text { adopted to } \\
\text { the student's level of knowledge }\end{array}$ & $3.66 \pm 0.80$ & $3.22 \pm 0.88$ & $3.35 \pm 1.16$ & $3.25 \pm 1.03$ \\
\hline 14 & $\begin{array}{l}\text { The volume of information covered in session was } \\
\text { Appropriate }\end{array}$ & $3.65 \pm 0.82$ & $3.13 \pm 0.99$ & $3.46 \pm 1.16$ & $3.62 \pm 0.76$ \\
\hline 15 & The sessions were clearly structured & $3.50 \pm 0.93$ & $3.07 \pm 0.93$ & $3.24 \pm 1.05$ & $3.63 \pm 0.73$ \\
\hline 16 & $\begin{array}{l}\text { The content covered in session was consistent with } \\
\text { the learning objectives presented at the start of } \\
\text { session }\end{array}$ & $3.71 \pm 0.93$ & $3.15 \pm 0.95$ & $3.67 \pm 1.13$ & $3.73 \pm 0.73$ \\
\hline 17 & $\begin{array}{l}\text { The session provided a good combination of } \\
\text { knowledge } \\
\text { conveyed by the teaching fellow and active student } \\
\text { participation }\end{array}$ & $3.69 \pm 0.95$ & $3.27 \pm 0.95$ & $3.48 \pm 0.99$ & $3.95 \pm 0.89$ \\
\hline \multirow[t]{2}{*}{18} & $\begin{array}{l}\text { I had sufficient opportunities to examine patients } \\
\text { during the session }\end{array}$ & $3.34 \pm 1.07$ & $3.33 \pm 1.14$ & $2.63 \pm 1.17$ & $2.10 \pm 1.02$ \\
\hline & $\begin{array}{l}\text { Overall mean } \pm \text { standard deviation of subscale } \\
\text { Teaching fellow }\end{array}$ & $3.59 \pm 0.70$ & $3.19 \pm 0.66$ & $3.30 \pm 0.66$ & $3.23 \pm 0.41$ \\
\hline 19 & Treated students with respect & $4.07 \pm 0.97$ & $3.52 \pm 0.94$ & $3.35 \pm 1.27$ & $2.62 \pm 0.94$ \\
\hline 20 & $\begin{array}{l}\text { Sufficiently responded to the students' questions } \\
\text { and participation }\end{array}$ & $4.12 \pm 0.87$ & $3.68 \pm 1.08$ & $3.44 \pm 0.98$ & $3.12 \pm 0.78$ \\
\hline 21 & Gave the students constructive feedback & $3.66 \pm 0.94$ & $3.47 \pm 1.08$ & $3.41 \pm 1.09$ & $2.88 \pm 0.77$ \\
\hline 22 & $\begin{array}{l}\text { Stated the principle learning objectives at the } \\
\text { beginning of session }\end{array}$ & $3.59 \pm 1.12$ & $3,40 \pm 1.27$ & $3.26 \pm 1.29$ & $2.42 \pm 1.12$ \\
\hline 23 & $\begin{array}{l}\text { Gave me personal feedback on my physical } \\
\text { examination skills }\end{array}$ & $3.22 \pm 1.17$ & $3.05 \pm 1.18$ & $3.04 \pm 1.14$ & $2.15 \pm 1.40$ \\
\hline 24 & $\begin{array}{l}\text { Delivered the session in a way that furthered my } \\
\text { personal interest for the subject matter }\end{array}$ & $3.63 \pm 1.02$ & $3.25 \pm 1.06$ & $2.98 \pm 1.25$ & $3.33 \pm 0.98$ \\
\hline 25 & $\begin{array}{l}\text { Gave me sufficient opportunities to apply my } \\
\text { theoretical } \\
\text { knowledge clinically }\end{array}$ & $3.46 \pm 1.04$ & $3.67 \pm 1.09$ & $2.81 \pm 1.08$ & $2.92 \pm 0.85$ \\
\hline 26 & $\begin{array}{l}\text { Explained how to interpret the physical } \\
\text { examination findings }\end{array}$ & $3.69 \pm 0.98$ & $3.38 \pm 1.01$ & $3.30 \pm 1.03$ & $3.68 \pm 0.72$ \\
\hline 27 & $\begin{array}{l}\text { Practiced clinical examination methods with } \\
\text { students }\end{array}$ & $3.78 \pm 0.95$ & $3.47 \pm 0.89$ & $3.15 \pm 1.03$ & $2.98 \pm 0.94$ \\
\hline 28 & $\begin{array}{l}\text { illustrated the integration of clinical information } \\
\text { and reasoning using patients' example }\end{array}$ & $3.78 \pm 0.82$ & $3.21 \pm 0.84$ & $2.93 \pm 1.02$ & $2.97 \pm 0.78$ \\
\hline 29 & Expressed in an understandable way & $3.93 \pm 0.77$ & $3.35 \pm 0.96$ & $3.54 \pm 1.04$ & $3.17 \pm 0.78$ \\
\hline \multirow[t]{2}{*}{30} & Arrived in time & $3.57 \pm 1.11$ & $3.44 \pm 1.24$ & $3.75 \pm 1.04$ & $1.96 \pm 1.64$ \\
\hline & Overall mean \pm standard deviation of subscale & $3.70 \pm 0.67$ & $3.38 \pm 0.72$ & $3.23 \pm 0.73$ & $2.85 \pm 0.55$ \\
\hline
\end{tabular}

Table 4: Mean scores with standard deviation and $\mathrm{p}$ values of Public vs. Private medical colleges

$\begin{array}{lcccccc}\text { Subscales } & \text { Public VS Private } & \mathrm{n} & \text { mean } & \mathrm{SD} \pm & t & p \text {-value } \\ \text { Physical environment } & \text { KGMC \& KMC } & 128 & 2.87 & 0.48 & & \\ \text { Patient comfort and student attitude } & \text { PIMC \& KbMC } & 114 & 2.59 & 0.60 & 4.093 & 0.0001 \\ & \text { KGMC \& KMC } & 128 & 3.06 & 0.50 & 1.81 & 0.07 \\ \text { Teaching session } & \text { PIMC \& KbMC } & 114 & 2.92 & 0.68 & & 0.09 \\ & \text { KGMC \& KMC } & 128 & 3.40 & 0.71 & 1.70 & \\ \text { Teaching fellow } & \text { PIMC \& KbMC } & 114 & 3.26 & 0.53 & & 0.0001\end{array}$

